Oliva, C. A., and Granja, A.D.., (2019). "Target Value Design in Real Estate Context: a Concpetual Map Model" In: Proc. 27 th Annual Conference of the International. Group for Lean Construction (IGLC), Pasquire, $\quad C$ and Hamzeh F.R. (Ed), Dublin, Ireland, pp. 1479-1492. DOI: https://doi.org/10.24928/2019/0273. Available at: 〈www.iglc.net>.

\title{
TARGET VALUE DESIGN IN REAL ESTATE MARKET: A CONCEPTUAL MAP MODEL
}

\author{
Carolina Asensio Oliva ${ }^{1}$, Ariovaldo Denis Granja ${ }^{2}$
}

\begin{abstract}
The Target Value Design (TVD) approach has been successfully used mainly in healthcare projects, delivering products with higher added value in the users'perspectives, and mainting the projects targets and stakeholders expectations under control. However, the use of this approach in other contexts, such as the real estate market, has been little explored. Therefore, there is an opportunity to deepen the discussion of the adoption of the current TVD benchmark in the real estate market. For these reasons, this work sought to (i) elaborate a conceptual map with the elements of the TVD, offering a graphic and visual insight to ease the integration of concepts and its associations, as well as classifying concepts, tools, catalysts, and ii) insert, in this Conceptual Map, particular externalities of the real estate market context through the methodological approach of Design Science Research. In this way, this work contributes to a discussion of the adoption of the TVD in other contexts, bringing an organization of the practices from its original benchmark.
\end{abstract}

\section{KEYWORDS}

Target Value Design; Conceptual Map, Real Estate

\section{INTRODUCTION}

The construction sector coexists with the conception of complex products and has some peculiar characteristics, inherent to their environment (Koskela, 1992). In such a context, there is a number of variables that influence the design process, such as: cost and schedule constraints, stakeholders from different areas of knowledge and a highly fragmented design process. In Brazil, in addition to the characteristics mentioned above, the construction sector counts with adversarial relationships, where private agendas often overlap the interests of the product as whole and where a collaborative environment is unusual and achieving it effectively can be quite challenging (Oliva, 2014; Melo and Granja, 2017; Neto, Costa and Ravazzano, 2018). On the other hand, the Target Value Design (TVD) consists of a proactive approach to cost management, encouraging collaboration among the

${ }^{1}$ PHD Architect - Former student of the University of Campinas, SP, Brazil. Contact email: carol_oliva@yahoo.com.br

2 PHD Professor, Construction Management Research Laboratory (LAGERCON), Department of Architecture and Construction, School of Civil Engineering, Architecture and Urban Design, University of Campinas, Campinas, SP, Brazil.. Contact email: adgranja @ fec.unicamp.br. 
stakeholders, and positioning costs and the value perspective for the end user as drivers of the design process. (Ballard and Reiser, 2004; Macomber, Howell and Barberio, 2007; Ballard, 2011).

Evidences from the literature show that TVD has been successfully adopted in the construction sector, promoting collaboration between the teams involved in the design process (architects, complementary designers, contractors, suppliers, customers), adding value to the product, launching them faster and with the budget under control (Denerolle, 2013; Do, Chen, et al., 2014; Do, Ballard and Tillmann, 2015; Melo, Doahn, et al., 2015). In the USA, where TVD was first conceived, these concepts have been applied efficiently, reducing costs and adding value to products, particularly in the healthcare environment (Ballard and Reiser, 2004; Macomber, Howell and Barberio, 2007; Rybkowski, Munankami, et al., 2011; Zimina, Ballard and Pasquire, 2012; Denerolle, 2013);(Do, Chen et al., 2013), energy efficiency retrofit projects (Lee, 2012), schooling (Ballard and Reiser, 2004) and have been mentioned even in less collaborative environments or with more adverse characteristics (Denerolle, 2013; Melo, Doahn, et al., 2015).

However, successful cases of application in other contexts and situations have been little explored, due to the specificities of development of certain types of products in the sector. Specifically, the potential of the use of TVD in the development of products with units for sale in the real estate sector has been little discussed so far (Oliva, 2014, Oliva and Granja, 2015; Neto, Costa and Thomas, 2016; Oliva et al., 2016) .This context, mainly in Brazil, presents some challenging characteristics for a TVD adoption, since its philosophy presupposes collaborative relationship and setting the cost of the product as a driver for the design process.

In the real estate market, some restrictions are imposed from an environment outside the business case itself, unlike the traditional applications of the TVD, where these restrictions are defined mainly in the internal domain of the project. One of such external imposed restriction is the price of the selling unit, which is defined by the benchmark in the real estate market, influenced by the existing demand for similar products. In addition, this price must be set according to how much a potential buyer is willing and able to pay to obtain certain benefits offered by such a product.

Besides the need for an adaption for real estate market use, the TVD approach according to its current benchmark (Ballard, 2011) proposes 17 elements, which range from tools and techniques to concepts and constructs. Therefore, there is a research opportunity for clarifying and extending the existing current benchmark of TVD for possible adoption in the real estate market, observing its implications. Therefore, the aim of this paper is to propose an extended conceptual map model for TVD adoption in the development of products with units for sale in the real estate market.

\section{CONCEPTUAL MAPS}

Considering a qualitative study, the development and use of a new theory may pose some obstacles for common uderstanding. In order to clarify the understanding of a new theory, several tools can be used, such as the Conceptual Maps (CM) (Maxwell, 2012). The CM 
was developed primarily by Joseph Novak (Maxwell, 2012) in order to understand how students learned and later it became a learning tool.

The $\mathrm{CM}$ for a given theory represents a visual structure that explains graphically what is being studied (MAXWELL, 2012). It is a tool that assists in the development and presentation of a conceptual structure in a visual form of a theory, and are formed by two parts: first, concepts, contained in boxes or circles, and second, the relations between these theoretical concepts. In addition, it also presents the so-called connectors, words that link concepts and express relationships between them (Novak and Cañas, 2008).

The CMs can be created for a variety of purposes, such as: (i) Adding and making visible implicit information contained in existing theories or clarifying an existing theory, allowing to observe the implications of such a theory and its limitations and (ii) To develop theory as a way of "putting on paper," assisting in the observation of unexpected connections or to identify gaps or contradictions in a given theory and helping to find solutions for these issues (Maxwell, 2012).

\section{RESEARCH METHOD}

This work used the Design Science Research (DSR) as a research strategy. When observing traditional sciences, such as the natural and social sciences, these present results that seek to explain, describe, explore or predict phenomena and their relations (Dresch, Lacerda and Júnior, 2015). However, when the objective of the research is to study a project, the construction or creation of a new artifact, or, in the case of works dedicated to problem solving, the field of traditional sciences presents limitations. In this case, DSR can be more adequate for this type of research (Dresch, Lacerda and Junior, 2015). The researches that best fit the DSR methodology are usually studies that search for: problem solving, innovations, methods, models, product and process improvements (Koskela, 2012). In general, this type of research contains verbs such as design, build, change, improve, develop, enhance, correct, adapt, adapt, extend, introduce (Jarvinen, 2004).

The literature review points out that the TVD approach, has efficiently applied in healthcare context (Ballard e Reiser, 2004); (Macomber, Howell e Barberio, 2007); (Rybkowski, Munankami, et al., 2011); (Zimina, Ballard and Pasquire, 2012); (Denerolle, 2013); (Do et al., 2014). However, some externalities wield influence in the product development process for the real estate market situation, which need to be considered. In addition, the current TVD benchmark does not structure its elements into various levels of abstraction, such as concepts, techniques, tools and catalysts. CM as an artifact can ease the understanding of the different elements of the TVD benchmark according to the various levels of abstraction and their associations as well. This levels of abstraction classification has the main advantage of helping to clarify the understanding of management approach, especially in contexts in which the TVD is not yet applied, where the mindset still deals with tradictional management technicques. Furthermore, adding to the CM the externalities inherent of the context of the real estate market can provide revealing insights for the possible adoption of TVD in this situation. 
The CM proposed underwent several evaluation cycles with so-called focus groups. In DSR, focus groups represent one of the tools for evaluating the artifact (Dresch, Lacerda and Junior, 2015). The use of focus groups (FG) allows for a more in-depth and collaborative discussion about the artifacts, and allows the combination with other techniques, as well as presenting low cost and supply of valid and reliable data (Dresch, Lacerda and Júnior, 2015; Trad, 2009). This approach allows the critical analysis of the outcomes of the work and creating possibilities for new and better solutions to the problem. The research FG gathered four academics with great knowledge and research on TVD, as well as related topics such as Lean, Target Costing and Integrated Project Delivery.

\section{TVD CONCEPTUAL MAP}

\section{DEFINING THE CONCEPTS, TOOLS AND CATALYSTS}

The next stage of CM construction, a classification was proposed, using as reference the TVD Benchmark (Ballard, 2011) and the basis of the three groups proposed by Denerolle (2013) (in this study, the author classifies the TVD benchmark into three categories: organization, defining and steering), with some adaptations to enable the construction of the CM. By analyzing each one of the 17 points of the TVD, three categories were proposed: Definition (in terms of viability), Organization (in terms of behavior and communication) and Organization (related to commitment).

The first group, Definition (viability), brings the elements of TVD related to the feasibility study, which have great importance in the process. It originates cost, scope, schedule and constraints of a new product and the alignment between means, ends and constraints is sought, in addition to the early involvement of stakeholders in the business case, assigning goals to those involved and establishing the constraints of the product.

The second group, Organization (behavior and communication), brings together the elements related to the understanding the product, seeks collaborative work among those involved and the facilitation of the exchange of information between the stakeholders during the product development process. The objective is to align the behavior of those involved in a collaborative way, often through incentive agreements and partnerships, and seek efficient communication among all, to meet the targets set in the definition phase, always looking to achieve the established value expectations.

The last group also refers to the Organization, but in terms of commitment of those involved in the process. This commitment takes place in the sphere of established targets, especially costs and schedule, and the commitment of the teams in the efficiency, decision making in different project solutions, and controlling all the constraints.

A second phase of this construction allowed us to identify the main constructs for insertion into the CM, through the elements: what / how / stakeholders / objectives and their relations. This evaluation was performed for each elements of the TVD. Finally, the catalysts and/or related tools for each element (if any) are pointed out. This organization can be seen in Frame 1 below. 
Target Value Design in Real Estate Context: a Concpetual Map Model 


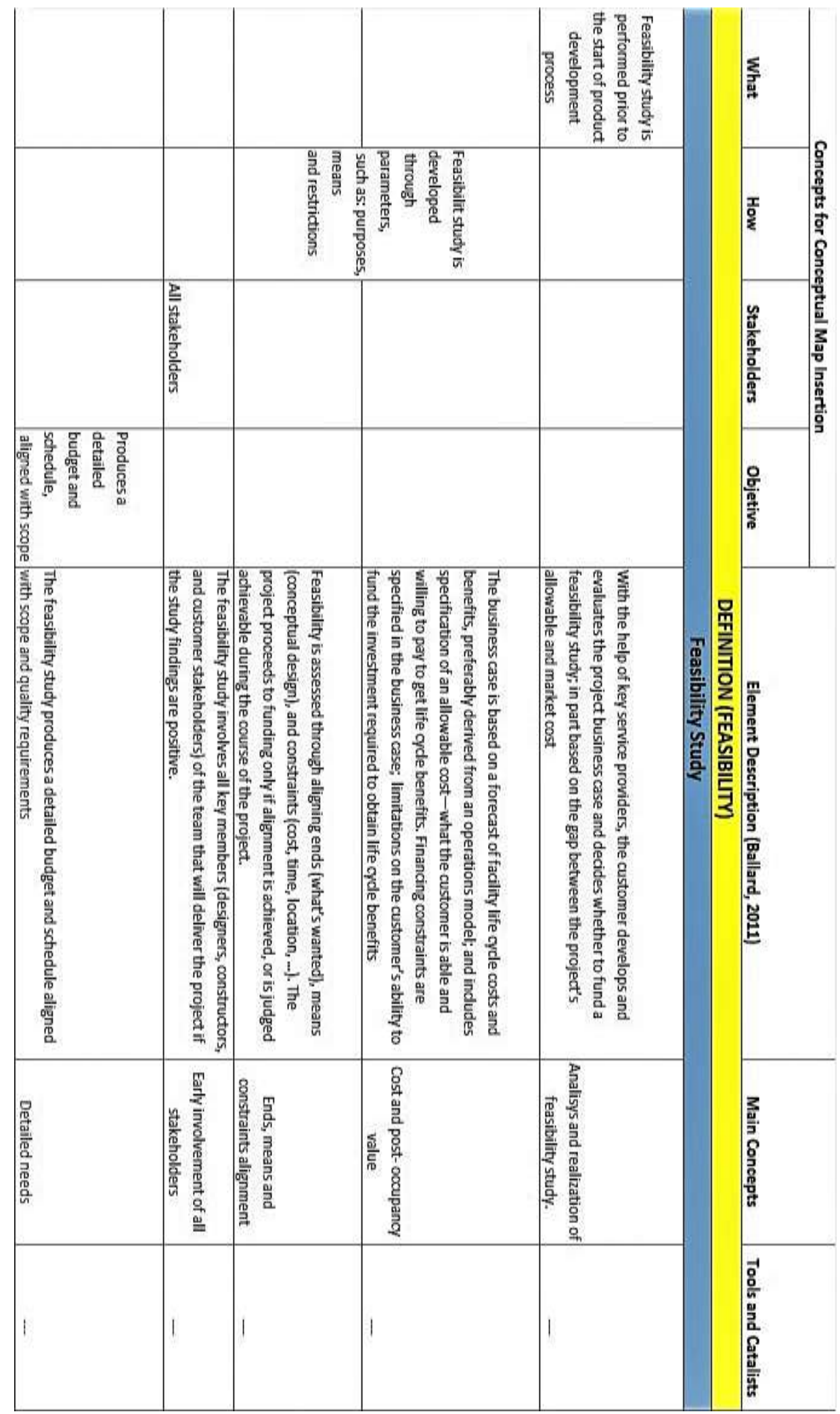

Figure 1: TVD Concept Map Organization 


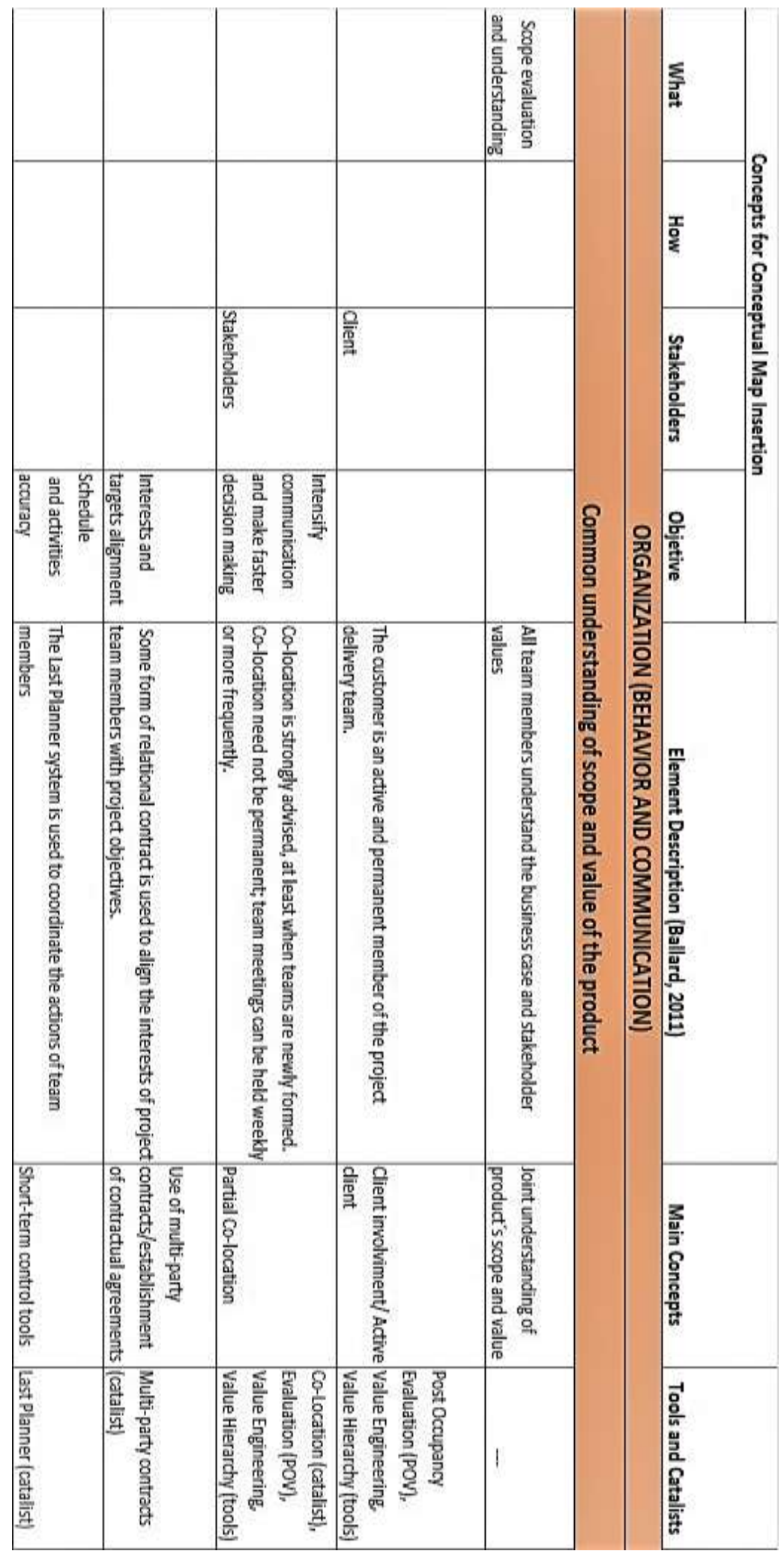

Figure 1: TVD Concept Map Organization (cont.) 


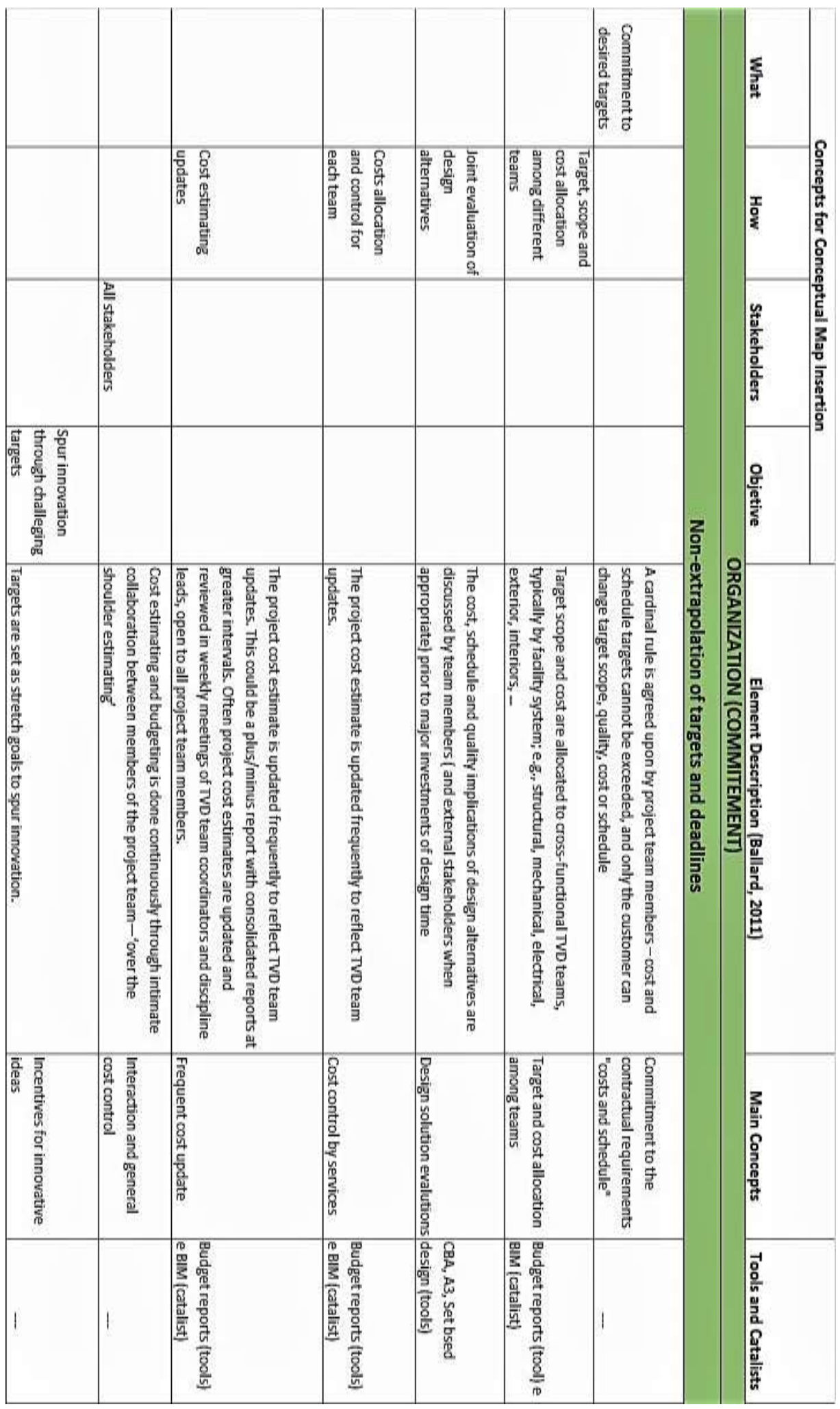

Figure 1: TVD Concept Map Organization (cont.) 
In addition to the organization of the elements of the TVD benchmark, we sought to couple in the Conceptual Map the externalities inherent to the real estate market context. Previous studies (Oliva, 2014; Oliva e Granja, 2015; Melo et al, 2015), have shown that these externalities are mainly related to: (i) fierce competition through the offer of similar products by competitors in this type of context; (ii) launch time for new products in general is very long in these companies, causing loss of competitive advantage; (iii) there is difficulty in capturing and understanding the value perspective of this final customer, considering that its client is external to the process and (iv) in the real estate market, the price of the product is defined externally, due to market pressures. Those researches collected data with several practioners in the real state market context, and they were used as basis for the main externalities proposed in the map, that are often highlighted by those professionals.

After de analisis of Figure 1, the Final Conceptual Map turned into the following configuration, as Figure 3 shows.

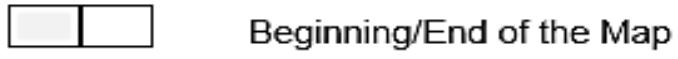

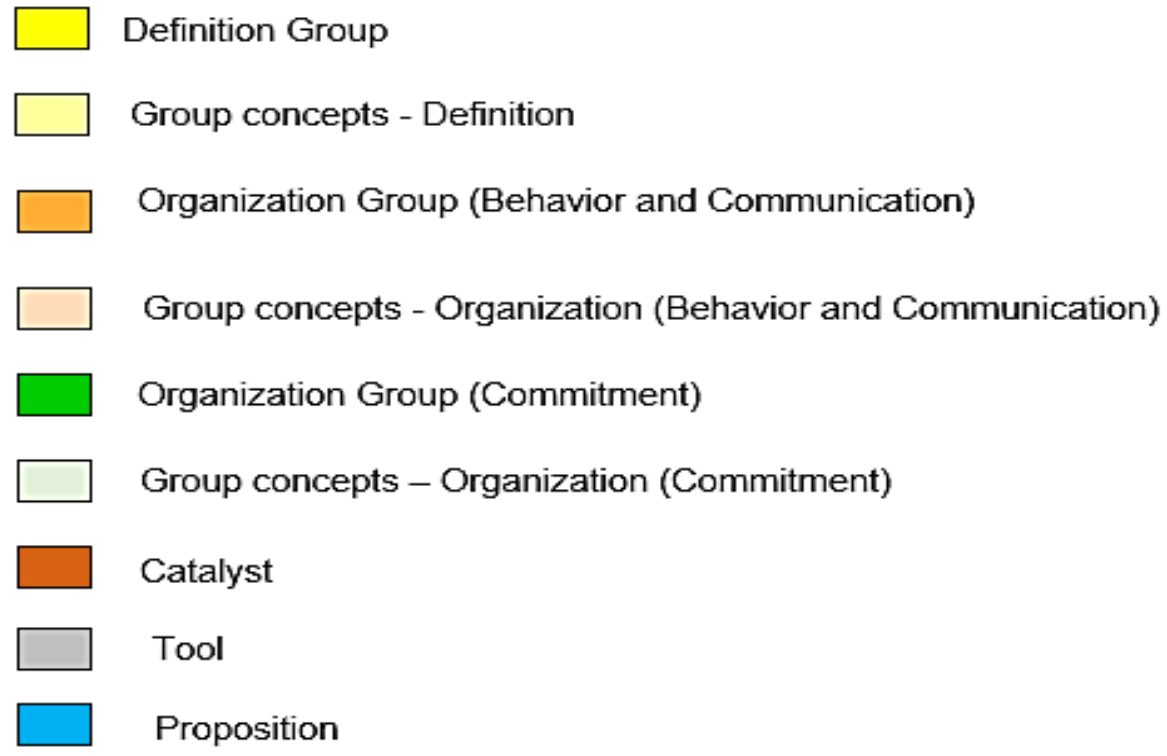

Externalities typical of the real estate context that influence the product development process

Figure 2: Captions for Conceptual Map 


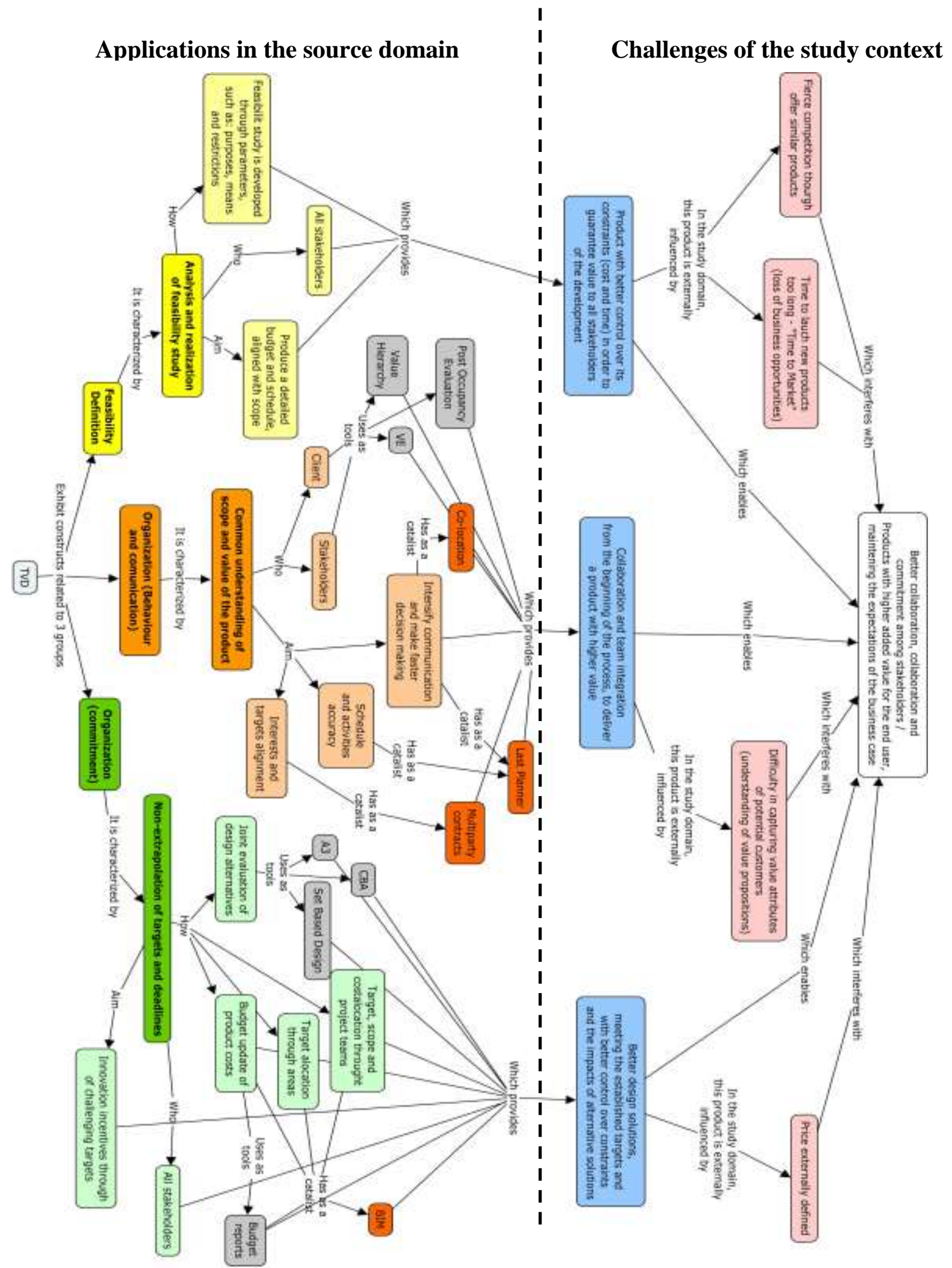

Figure 3: TVD Conceptual Map for the Real Estate Context 


\section{CONCLUSIONS}

The research has deepened the discussion of the adoption of the current TVD benchmark in the real estate market.The construction of a conceptual map as an artifact has started by identifying the constructs that would be part of the map and has established relationships between them. For this reason, the first step has involved identifying and classifying the constructs present in the current TVD benchmark, establishing relationships to enable the construction of the map, where the interaction with the focus groups was essential to obtain the CM. It was necessary to identify principles, catalysts, tools, objectives, parties involved. This is highlighted as the first result of the theoretical work.

After the organization and classification of the constructs, the elaboration of the conceptual map took place, which has allowed a graphic visualization of the elements of the TVD and the relation between them, as well as the propositions for which they were intended. In addition, the peculiarities inherent to the study context were inserted, especially the externalities which influence the process of developing products with units for sale in the real estate context. In addition, searching the literature, the authors couldn't find any precursors proposing new collaborative practices through a visual structure such as a conceptual map.

The main contributions of this research were the following: (i) Classification of the TVD benchmark concepts into groups and associations between them ; (ii) Proposal with elements of TVD adapted to the real estate context with inclusion of externalities characteristic of the real estate, which directly influence the product development process and (iii) Results of the organization and relationships between the constructs, which represent the results that each set of constructs can achieve, and how these propositions aim at the final goal of the adoption of the TVD.

The authors acknowledge that the size of the focus groups proposed (with 4 partcipants) can be a limitation for the proposed conceptual map. Nevertheless, the results can be highlited as a first attempt to organize the TVD approach into a more conceptual and graphic structure, considering the particularities of a new context of application.

\section{ACNOWLEDGMENTS}

The authors would like to thank the academics who participated in this study, providing important insights during the focus groups to construct the conceptual map. The authors also thank CAPES (development agency) for the financial support.

\section{REFERENCES}

Ballard, G. Target Value Design: Current Benchmark. Lean Construction Journal, 2011. 79-84.

Ballard, G.; Reiser, P. (2004).The St. Olaf College Fieldhouse project: a case study in designing to target cost. Proceedings, International Group for Lean Construction. Dinamarca: [s.n.]. 
Denerolle, S. (2013). The application of Target Value Design to the design phase of 3 hospital projects. Project Production Systems Laboratory - University of California. Berkeley.

Do, D. et al. (2014). Target Value Design as a Method for Controlling Project Cost Overruns. Proceedings IGLC-22, June 2014. Oslo, Noruega: [s.n.]. p. 171-181.

DO, D.; Ballard, G.; Tillmann, P. (2015). Technical Report: Part 1 of 5: The Application of Target Value Design in the Design and Construction of the UHS Temecula Valley Hospital. Project Production Systems Laboratory - University of California, Berkeley. Berkeley, CA - USA.

Dresch, A.; Lacerda, D. P.; Júnior, J. A. V. A. (2015).Design Science ResearchA Method for Science and Technology Advancement. 2015 edition. Porto Alegre: Bookman.

Koskela, L. (1992). Application of new product philosophy to construction. Stanford CA: Center for integrated facility engineering. Stanford University. (n.72).

Lee, H. W. (2012). Application of Target Value Design to energy efficiency investments. University of California. Berkeley.

Macomber, H.; Howell, G.; Barberio, J. (2007).Target Value Design: Nine Foundational Practices for Delivering Surprising Client Value. The American Institute of Architects, Practice Management Digest.

Maxwell , J. A.(2012). Designing a qualitative study. In: Maxwell, J. A. Qualitative Research Design: An Interactive Approach. $3^{\text {a }}$ Ed. ed. [S.1.]: Sage Publishing, Cp. 7, p. 214-253

Melo, R. S. S.; Granja, A. D. (2017) Guidelines for target costing adoption in the development of products for the residential real estate market. Ambiente Construído, Porto Alegre, Ambient. constr. vol.17 no.3 Porto Alegre

Neto, H. M. M.; Costa, D. B.; Thomas, L. (2016). Target Value Design Approach for Real Estate. Proc. 24th Ann. Conf. of the Int'1. Group for Lean Construction. Boston, MA, USA: [s.n.]. p. 63-72

Novak, J. D.; Cañas, J. (2008). The theory underlying concept maps and how to construct them. Technical Report IHMC CmapTools - Institute for Human and Machine Cognition. Florida, USA, p. 1-36.

Oliva, A. et al. (2016). Assessing suitability of Target Value Design adoption for real estate developers in Brazil. Proceedings, 24th International Group for Lean Construction. Boston: [s.n.]. p. 93-102.

Oliva, C. A. (2014). Proposta de integração do Target Value Design na gestão do processo de projeto em emrpreendimentos da construção civil - Dissertação de Mestrado. Universidade de Campinas. Campinas. (In Portuguese)

Oliva, C. A.; Granja, A. D. (2015). Proposta para adoção do Target Value Design (TVD) na gestão no processo de projeto de empreendimentos imobiliários. Ambiente Construído, Porto Alegre, Outubro/Dezembro 131-147. (In Portuguese)

Ravazzano, T. C. (2016). Diretrizes para implementação do Target Value Design em empreendimentos imobiliários - Trabalho de Conclusão de Curso. Universidade Federal da Bahia. Salvador, p. 70. (In Portuguese) 
Rybkowski, Z. K. et al. (2011).Toward an Understanding of Cost and Aesthetics: Impact of Cost Constraints on Aesthetic Ranking Following Target Value Design Exercises. Proceedings; IGLC. Peru: [s.n.].

Zimina, D.; Ballard, G.; Pasquire, C. (2012).Target value design: using collaboration and a lean approach to reduce construction cost. Construction Management and Economics, Maio 2012. 383-398. EE, H. W. Application of Target Value Design to energy efficiency investments. University of California. Berkeley. 
Oliva, C. A., and Granja, A.D.

Proceedings IGLC - 27, July 2019, Dublin, Ireland 